\title{
Permanently split capacitor motor-study of the design parameters
}

\author{
Vasilija Sarac, Goce Stefanov*
}

\begin{abstract}
Paper analyzes the influence of various design parameters on torque of permanently split capacitor motor. Motor analytical model is derived and it is used for calculating the performance characteristics of basic motor model. The acquired analytical model is applied in optimization software that uses genetic algorithms (GA) as an optimization method. Optimized motor model with increased torque is derived by varying three motor parameters in GA program: winding turns ratio, average air gap flux density and motor stack length. Increase of torque has been achieved for nominal operation but also at motor starting. Accuracy of the derived models is verified by Simulink. The acquired values of several motor parameters from transient characteristics of Simulink models are compared with the corresponding values obtained from analytical models of both motors, basic and optimized. Numerical analysis, based on finite element method (FEM), is also performed for both motor models. As a result of the FEM analysis, magnetic flux density in motor cross-section is calculated and adequate conclusions are derived in relation to core saturation and air gap flux density in both motor models.
\end{abstract}

K e y w o r d s: permanently split capacitor motor, parametric analysis, genetic algorithms, transient characterisitcs, finite elements method

\section{Introduction}

The permanently split capacitor (PSC) motor is one of the widely used single-phase motors. Most of the singlephase motors utilize an auxiliary (start) winding on the stator side to produce a starting torque. Usually, this winding is disconnected after the acceleration of the motor. The PSC motor has neither a starting switch, nor a capacitor strictly for starting. Instead, it has a runtype capacitor, permanently connected in series with the start winding. This makes the start winding an auxiliary winding once the motor reaches the running speed. Because the run capacitor must be designed for continuous use, it cannot provide the starting boost of the starting capacitor. Typically, starting torques of PSC motors are low, from 30 to $150 \%$ of the rated torque, so these motors are not for hard-to-start applications [1]. Searching for a motor design of maximum starting torque or maximum efficiency are objectives of the optimization. Some authors propose surrogate circuit-field model that, exploits a polynomial surrogate model and genetic algorithm to find minimum of the objective functions [2]. In addition, variation of the capacitance, as a method for torque increasing, is analyzed [3]. Optimization of torque and efficiency at single-phase motors is a complex issue, which besides design parameters (stator and rotor slots, stator windings) involves also the core material and its influence on magnetic flux density [4]. Particle swam optimization method is one of the optimization methods used for obtaining the dimensions of the single-phase motor which correspond to the maximum efficiency [5]. This paper proposes mathematical model of single-phase permanently split capacitor motor suitable for application in GA optimization software in terms of the torque optimization. Optimized model $(\mathrm{OM})$ is derived with three varied parameters: turns ratio of the auxiliary and the main stator winding-a, flux density in air gap of the motor- $\mathrm{B}_{\delta}$ and axial length of stator core-L. Study is performed on FMR 35/6 PSC motor (Fig. 1), produced by company MicronTech. The main objective of this study is to increase the output torque of the motor and to improve its operating characteristics ie efficiency factor or power factor. By increasing the output torque, is expected motor operation to improve in terms of the motor coupling to the load. The study is performed on a motor that was randomly selected.

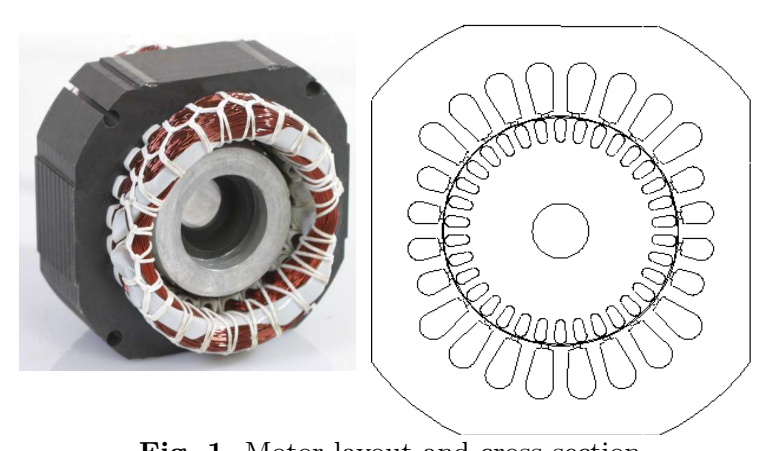

Fig. 1. Motor layout and cross-section

In this specific case, GA has fast convergence towards the optimal solution since the number of varied parameters is relatively small and the analyzed model has only one objective function, which means that there is only a single criterion for the solution. The mathematical model

\footnotetext{
* Faculty of Electrical Engineering, University Goce Delcev, P.O.Box 201, 2000 Stip, Macedonia, vasilija.sarac@ugd.edu.mk; goce.stefanov@ugd.edu.mk
} 
of the motor is derived based on the motor exact geometry, and the accuracy of this basic motor model (BM) is verified by an experiment. The accuracy of the optimized model is verified by comparing the output results of motor currents, speed and torque from Simulink model of the motor with the corresponding results from GA model. Finite elements analysis (FEA) is applied on both motor models, basic and optimized. Finite Element Method (FEM) analyzes impact of the design modifications at optimized model, on magnetic flux density in the motor cross-section and on the flux density in the air gap. Performed numerical analysis, resulting in magnetic flux density in motor cross-section and in the air gap, provides a useful insight into electromagnetic processes inside the machine. Additionally, parts of the motor construction with high flux density near to the point of core saturation can be easily detected.

\section{Mathematical model of the basic model}

Mathematical models of the single-phase motors are based on the double-field revolving theory. The method of symmetrical components is used as a mathematical tool and consequently the unsymmetrical currents and voltages of the two stator windings of the PSC motor, denoted as general vector A (Fig. 2), may be decomposed into two symmetrical systems consisting of forward and backward or direct and inverse components of the symmetrical systems $[6-12]$.

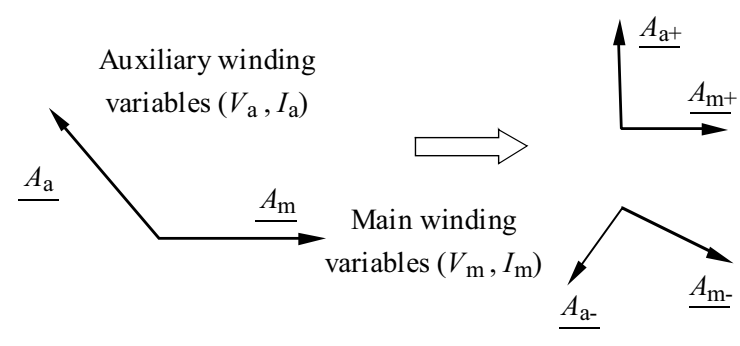

Fig. 2. Symmetrical components of two-phase motor

Operating characteristics of the motor are calculated by the method of symmetrical components. The first step in their calculation is to determine all motor parameters: $R_{\mathrm{sm}}$-main stator winding resistance, $X_{\mathrm{sm}}$-main winding leakage reactance, $R_{\mathrm{sa}}$-auxiliary stator winding resistance, $X_{\mathrm{sa}}$-auxiliary stator winding leakage reactance, $X_{\mathrm{mm}}$-magnetization reactance, $R_{\mathrm{rm}}$-rotor winding resistance, $X_{\mathrm{rm}}$-rotor winding leakage reactance. The calculation of the parameters is based on data from the motor producer regarding the stator and rotor dimensions, the number of the slots and the length of the air gap. After determining the rotor parameters, the direct and inverse impedances of the main stator winding and $\mathcal{Z}_{m+}, \mathcal{Z}_{m-}$ and the mutual impedance between the main and auxiliary winding $\mathcal{Z}_{a}^{m}$ are determined as well. They are used in the calculation of direct and inverse components of the current in the main stator winding $\mathcal{I}_{m+}$ and $\mathcal{I}_{m-}[6]$.
The direct and inverse components of the rotor winding impedance $\mathcal{Z}_{r+}$ and $\mathcal{Z}_{r-}$ are calculated as well [8]. They allow the calculation of the direct and inverse components of the rotor currents and. The allow the calculation of the direct and inverse components of the rotor currents Ir+ and Ir-

$$
I_{s}=\left|\mathcal{I}_{m+}+\mathcal{I}_{m-}+j \frac{\mathcal{I}_{m+}-\mathcal{I}_{m-}}{a}\right|
$$

The currents in the main stator winding, the auxiliary winding and the rotor winding are calculated respectively:

$$
\begin{aligned}
I_{m} & =\left|\mathcal{I}_{m+}+\mathcal{I}_{m-}\right|, \\
I_{a} & =\left|j \frac{\mathcal{I}_{m+}-\mathcal{I}_{m-}}{a}\right|, \\
I_{r} & =\left|I_{r+}+\mathcal{I}_{r-}\right|
\end{aligned}
$$

where $a$ represents the ratio of turns of the auxiliary winding $\mathrm{N}_{\mathrm{a}}$ and of the main winding $\mathrm{N}_{\mathrm{m}}$. Direct and inverse components of electromagnetic torque are found from $[6]$ :

$$
\begin{aligned}
& T_{e+}=\frac{2 p}{\omega_{1}} I_{m+}^{2}\left[\operatorname{Re}\left(\mathcal{Z}_{+}\right)-R_{\mathrm{sm}}\right], \\
& T_{e-}=-\frac{2 p}{\omega_{1}} I_{m-}^{2}\left[\operatorname{Re}\left(\mathcal{Z}_{-}\right)-R_{\mathrm{sm}}\right] .
\end{aligned}
$$

$p$ is the number of pairs of poles and $\omega_{1}$ is the angular frequency. $Z_{+}$and $Z_{-}$are direct and inverse impedances calculated from the main and rotor winding parameters [6].

Electromagnetic torque is

$$
T_{e}=T_{e+}+T_{e-}
$$

Electromagnetic power is calculated from the parameters of rotor winding and motor slip $s$

$$
P_{\mathrm{em}}=\frac{2 R_{\mathrm{rm}}\left|I_{r+}\right|^{2}}{s}-\frac{2 R_{\mathrm{rm}}\left|I_{r-}\right|^{2}}{2-s} .
$$

Mechanical power is

$$
P_{\text {mech }}=P_{\mathrm{em}}(1-s)
$$

The output power is calculated from

$$
P_{2}=\frac{P_{\mathrm{mech}}}{1.015}
$$

The motor output power is obtained from the mechanical power decreased by the value of stray losses, often difficult to be measured. IEEE-125 specifies them as $0.9-1.8 \%$ of the motor output power. Input power is calculated from

$$
P_{1}=V_{s}\left|I_{s}\right| \cos \varphi
$$


Table 1. Comparison of calculated and measured data

\begin{tabular}{lcc}
\hline Rated operation, $s=0.04$ & & \\
Parameter & Mathematical model & Measurements \\
\hline Rated torque (Nm) & 0.412 & 0.402 \\
Rated supply current (A) & 1.6 & 1.32 \\
Maximum output power (W) & 215 & 210 \\
Maximal torque (Nm) & 0.766 & 0.80 \\
Starting, $s=1$ & & \\
Starting torque (Nm) & 0.1 & 0.13 \\
Starting supply current (A) & 3.5 & 4 \\
\hline
\end{tabular}

Table 2. Output results from GA program

\begin{tabular}{lcccccc}
\hline $\mathrm{G}$ & $\begin{array}{c}\text { Best value-M } \\
(\mathrm{Nm})\end{array}$ & $\begin{array}{c}\text { Mean } \\
\text { value }\end{array}$ & $\begin{array}{c}\text { Stand. } \\
\text { deviat. }\end{array}$ & $\begin{array}{c}\mathrm{a} \\
(/)\end{array}$ & $\begin{array}{c}B_{\delta} \\
(\mathrm{T})\end{array}$ & $\begin{array}{c}\mathrm{L} \\
(\mathrm{m})\end{array}$ \\
\hline 1 & 0.43804 & 0.3195 & 0.0576 & 1.2613 & 0.76984 & 0.0335 \\
3000 & 0.7315 & 0.5522 & 0.0428 & 1.6982 & 0.79996 & 0.0369972 \\
6000 & 0.73212 & 0.2094 & 0.0068 & 1.6998 & 0.79996 & 0.0369993 \\
\hline
\end{tabular}

Table 3. Ranges of variations of input parameters

\begin{tabular}{lcc}
\hline & Variation range & $\begin{array}{c}\text { Output results } \\
\text { from GA }\end{array}$ \\
\hline Turns ratio a $(/)$ & $1.0-1.7$ & 1.69986 \\
Air gap flux density $\mathrm{B}_{\delta}(\mathrm{T})$ & $0.6-0.8$ & 0.79998 \\
Magnetic core length $\mathrm{L}(\mathrm{m})$ & $0.03-0.037$ & 0.036999 \\
\hline
\end{tabular}

$V_{s}$ is the motor supply voltage, $I_{s}$ the supply current and $\cos \varphi$ is the power factor.

Power factor is calculated from

$$
\cos \varphi=\frac{\operatorname{real}\left(I_{s}\right)}{I_{s}}
$$

Efficiency factor is calculated from

$$
\eta=\frac{P_{2}}{P_{1}}
$$

The accuracy of the derived mathematical model, or basic model of the motor (BM), is verified by comparing the obtained results of several motor parameters with the producer's data. This mathematical model will be the basis of the program for optimization of the output torque. Table 1 compares calculated and measured data for the rated operation or motor slip $s$ of 0.04 and during starting or slip $s$ equal to one.

\section{Optimized model of the motor}

\subsection{Methodology}

Genetic Algorithm is an optimization method, which allows for the most favorable solution of a particular optimization problem to be obtained in a fast and effective way. It belongs to the stochastic methods that form the basis of the theory of probability. Genetic algorithms and other related evolutionary algorithms (EAs) provide a framework for effectively sampling large search spaces and the basic technique is both broadly applicable and easily tailored to specific problems. There have been three independent implementation instances of EAs. GA, developed by Holland and thoroughly reviewed by Goldberg, evolution strategies (ESs) developed in Germany by Rechenberg and Schwefel and evolutionary programming (EP), originally developed by L.J. Fogel and subsequently redefined by D.B. Fogel. Each of these three algorithms has been proved yielding approximately optimal solutions. Success has been achieved for noisy and time-dependant landscapes. B Bäck and Fogel $[13,14]$, give descriptions that are more formal. The GA method is robust and reliable. It searches for an extreme of certain function within the complete area of possible solutions, thus avoiding location of the solutions that are not necessarily the global optimum [15-18]. The primary parameters in GA method are the size of the population $\mathrm{N}$ and the maximum number of generations $G$ of a certain input parameter (Table 2). The number of created generations is set to 6000 and the size of the population is set to 20. After all members of the population are created, program proceeds to the calculation of the fitness function of each member of the population ie calculation of the objective function. The input parameters vary within 
Table 4. Motor characteristics at rated load

\begin{tabular}{lcc}
\hline Variable & $\mathrm{BM}$ & $\mathrm{OM}$ \\
\hline Main stator winding current $I_{\mathrm{m}}(\mathrm{A})$ & 1.063 & 1.61 \\
Rotor current $I_{\mathrm{r}}(\mathrm{A})$ & 0.7062 & 1.183 \\
Auxiliary stator winding current $I_{\mathrm{a}}(\mathrm{A})$ & 0.6964 & 0.7468 \\
Supply current $I_{\mathrm{s}}(\mathrm{A})$ & 1.6774 & 2.259 \\
Power factor $\cos \varphi(/)$ & 0.997 & 0.98349 \\
Input power $P_{1}(\mathrm{~W})$ & 368 & 488.7 \\
Output power $P_{2}(\mathrm{~W})$ & 124 & 220.8 \\
Output torque $M(\mathrm{Nm})$ & 0.412 & 0.732 \\
Efficiency factor $\eta(/)$ & 0.3376 & 0.4517 \\
\hline
\end{tabular}

Table 5. Motor parameters

\begin{tabular}{lcc}
\hline Parameter & BM & OM \\
\hline Diameter of wire- main winding $d_{\mathrm{m}}(\mathrm{mm})$ & 0.67 & 0.73 \\
Diameter of wire- auxiliary winding $d_{\mathrm{a}}(\mathrm{mm})$ & 0.3 & 0.3 \\
Turns ratio $a(/)$ & 1.5 & 1.69 \\
Air gap flux density $\mathrm{B}_{\delta}(\mathrm{T})$ & 0.709 & 0.79 \\
Axial length of magnetic core $L(\mathrm{~m})$ & 0.035 & 0.037 \\
Main stator winding resistance $R_{\mathrm{sm}}(\Omega)$ & 13.419 & 9.51 \\
Main stator winding leakage reactance $X_{\mathrm{sm}}(\Omega)$ & 31.35 & 22.91 \\
Auxiliary stator winding resistance $R_{\mathrm{sa}}(\Omega)$ & 74.75 & 68.57 \\
Auxiliary stator winding leakage reactance $X_{\mathrm{sa}}(\Omega)$ & 52.9 & 49.66 \\
Rotor winding resistance $R_{\mathrm{rm}}(\Omega)$ & 10.38 & 7.399 \\
Rotor winding leakage reactance $X_{\mathrm{rm}}(\Omega)$ & 20.26 & 14.956 \\
Magnetization reactance $X_{\mathrm{mm}}(\Omega)$ & 425 & 469.31 \\
\hline
\end{tabular}

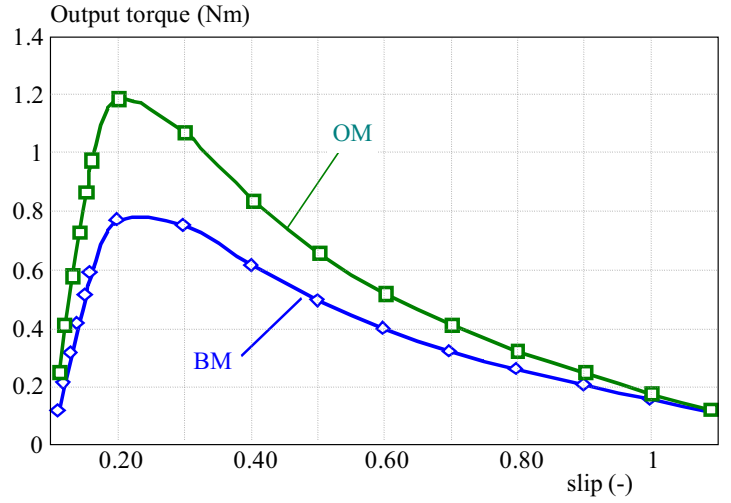

Fig. 3. Characteristic of output torque

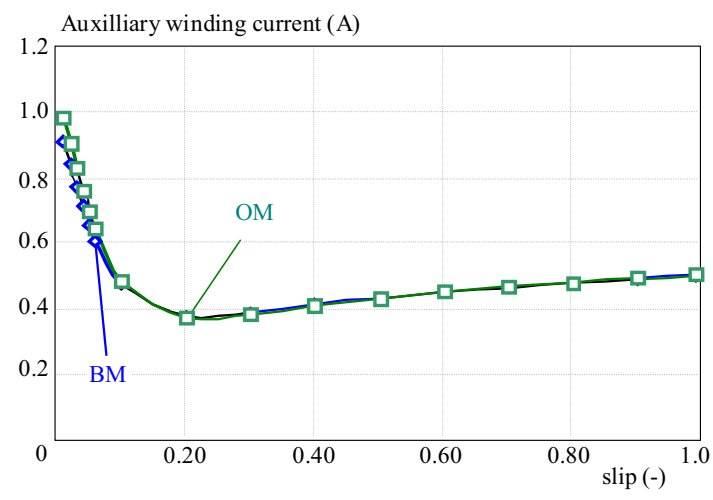

Fig. 5. Characteristics of auxiliary winding current

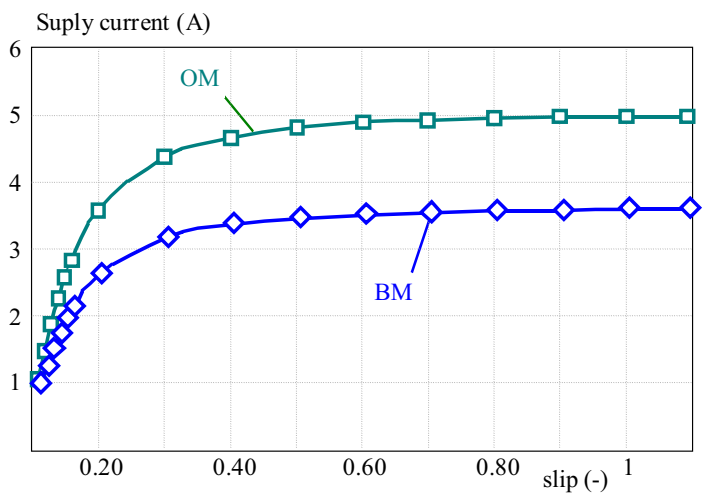

Fig. 4. Characteristic of supply current

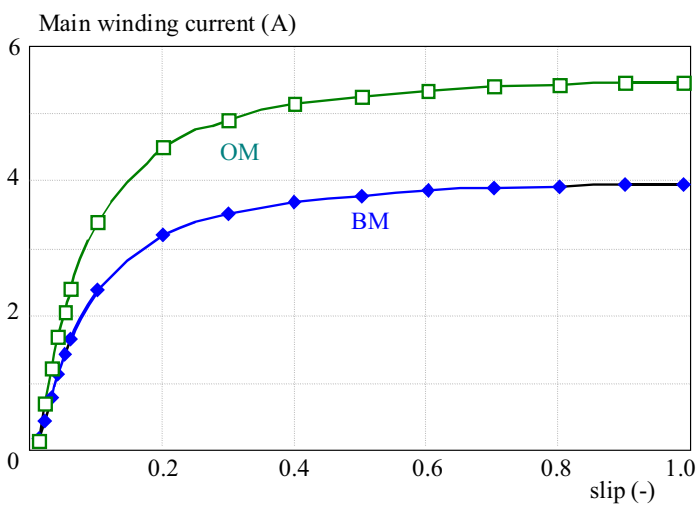

Fig. 6. Characteristic of main winding current 


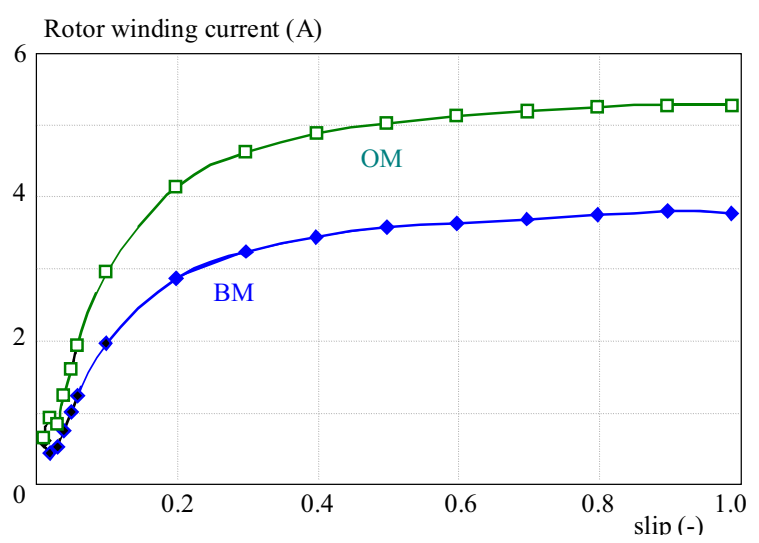

Fig. 7. Characteristic of rotor winding current

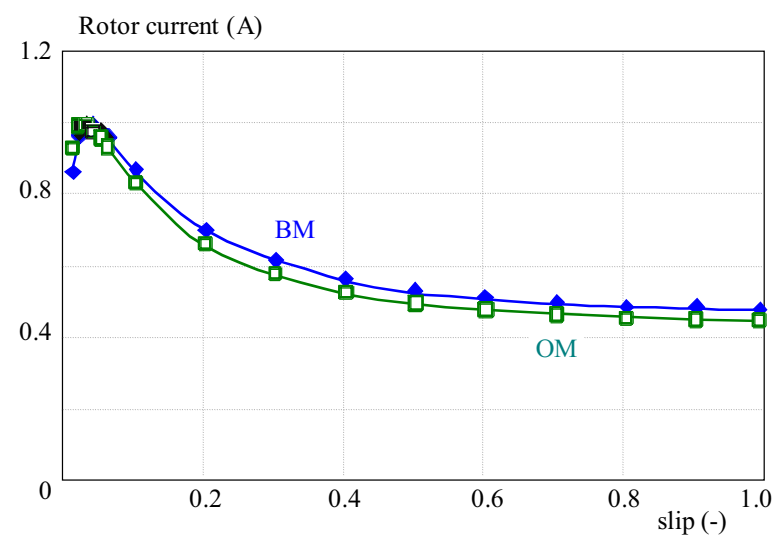

Fig. 9. Characteristic of power factor

defined boundaries, used for finding the optimal solution (Table 3).

In the basic model of the motor parameters $a, \mathrm{~B}_{\delta}$ and $L$ are constant and their values are $a=1.5, \mathrm{~B}_{\delta}=0.709$ and $L=0.035 \mathrm{~m}$. According to Table 3, the optimized model has $a=1.69986, \mathrm{~B}_{\delta}=0.799 \mathrm{~T}$ and $L=0.0369 \mathrm{~m}$ (output results from the GA program). All parameters and characteristics of the motor are calculated again for the new values of $a, \mathrm{~B}_{\delta}$ and $L$. This allows for a new optimized model of the motor to be created. Optimization is performed by taking into consideration some constraints, $i e$ the maximal voltage of the capacitor should not exceed $440 \mathrm{~V}$ and the currents in the stator windings should be within limits of the cross-section of the copper conductor [3].

\subsection{Results from optimization}

The obtained output results of the varied parameters from the GA program are used for calculating the parameters and the characteristics of the optimized motor model. They are presented in Tables 4 and 5 for both motor models, basic and optimized. All important operating characteristics of the motor such as main winding current, auxiliary current, supply current, power factor, input and output power, efficiency factor and output torque are calculated for the entire range of motor slips, $s=(0 \div 1)$ and for both motor models [19].

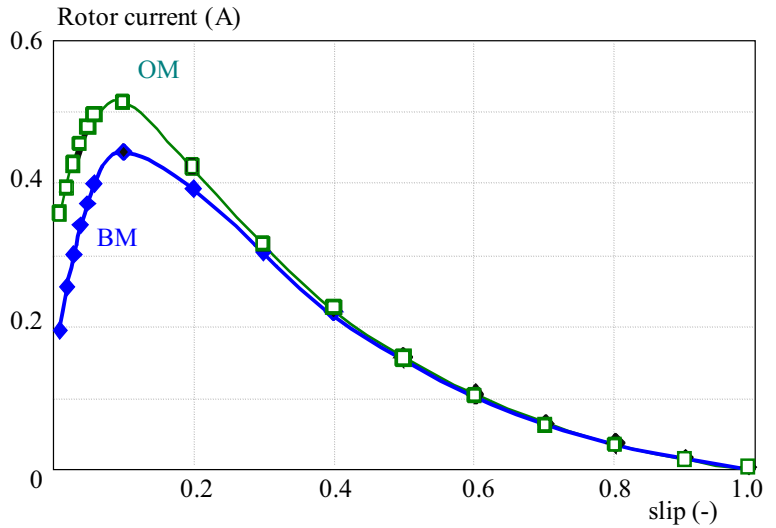

Fig. 8. Characteristic of efficiency factor

Figure 3 presents the output torque for different slips. Figures 4 to 7 illustrate the supply current, auxiliary winding current, main winding current and the rotor current of both motor models.

Figures 8 and 9 present the efficiency factor and power factor for different slips.

The small modifications in the construction of the motor contribute to the increase of the output torque. This is followed by an increase in the power consumption, the supply current and the output power. The output power in the optimized model is greater than the power in the basic model and this provides for a better efficiency factor of the optimized model. In both models of the motor, the power factor remains almost unchanged. Table 6 presents the torque values of both models for three typical operating modes: no load or motor slip of 0.01 , rated load or slip of 0.04 and motor starting or slip of 1 .

Table 6. Comparison of torque

\begin{tabular}{lcc}
\hline & Output torque $(\mathrm{Nm})$ & \\
slip- $s$ & BM & OM \\
\hline 0.01 & 0.106678 & 0.245 \\
0.04 & 0.412063 & 0.732 \\
1 & 0.107995 & 0.12 \\
\hline
\end{tabular}

\section{Simulnik models and results}

Very attractive new kind of simulation procedure introduced in the recent versions of the software package MATLAB/Simulink has been available for a few years [20]. Using the different system library blocks a powerful real-time model of the PSC motor can be built (Fig. 10). As the stator is provided with two orthogonal windings and the rotor is fully symmetric, the singlephase induction motor is suitable for direct application of d-q model in stator coordinates [21-23]. Figure 10 presents the motor model in Simulink. According to Table 5 in Simulink block of the single-phase capacitor motor parameters of basic and optimized motor are input. 


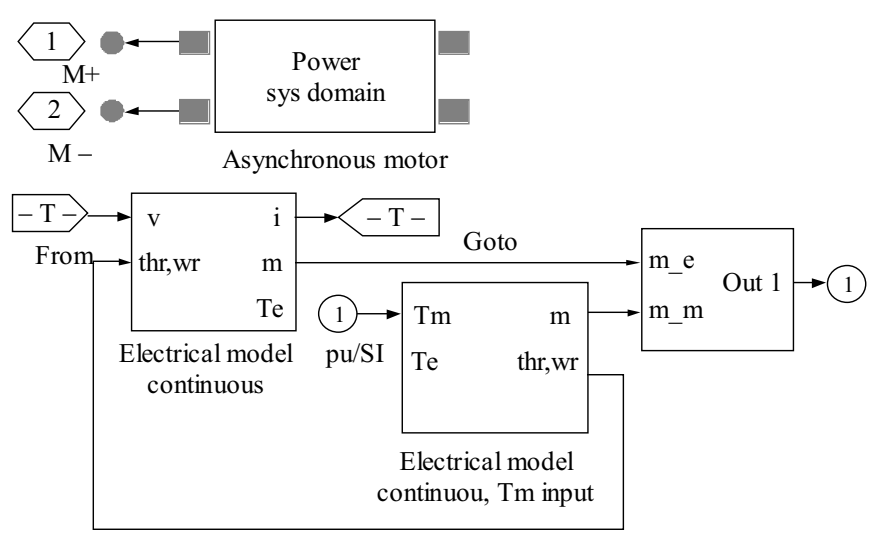

Fig. 10. Simulink motor model

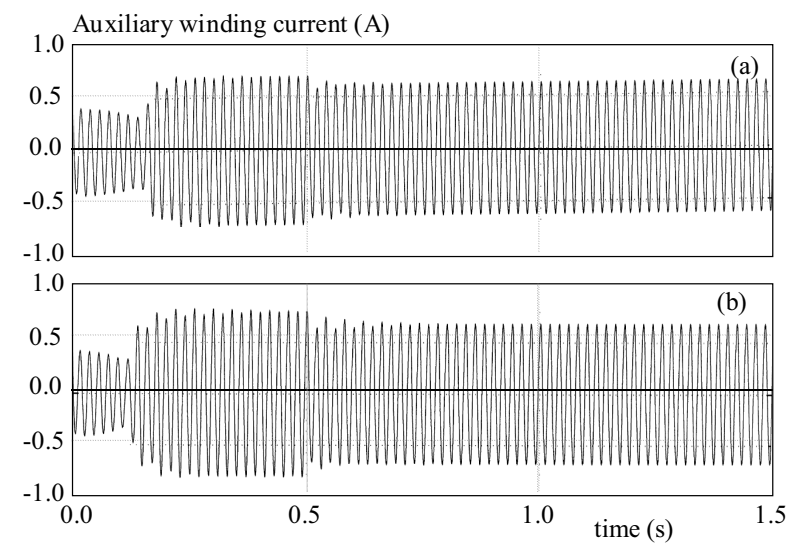

Fig. 12. Transient characteristics of auxiliary winding current

Simulink block of the single phase machine uses d,q frame transformation of voltage, currents and flux linkage. As an output from Simulink block of the single-phase machine, motor currents are obtained as well as electromagnetic torque, motor speed and capacitor voltage for both motor models basic and optimized. Figures 11 to 16 present motor transient characteristics of the main winding current, auxiliary winding current, supply current, motor speed, capacitor voltage and electromagnetic torque at nominal load for basic and optimized motor. After $0.5 \mathrm{~s}$, when motor acceleration ends, an external load is coupled to the motor shaft, providing nominal load working condition for motor.

Table 7 compares the rms values of the characteristics from the mathematical models of basic and optimized motor and from the respective simulation models. From the presented transient waveforms it is evident that the torque at the optimized model has increased as a result of increased supply current. The increased torque reduces the acceleration time of the motor (Fig. 14). After the acceleration time ends, the value of the current in the main stator winding is reduced from the starting current to the no-load current. In addition, 0.5 seconds after motor starting, the rated constant load is coupled to the motor shaft and consequently the current in the main stator winding reaches the value of the rated current. Capacitor voltage in both cases is within the prescribed limit of rms
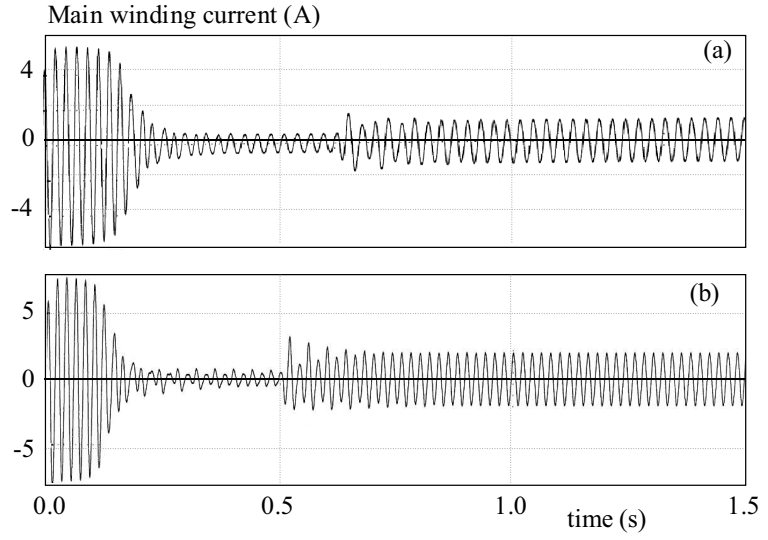

Fig. 11. Transient characteristics of main stator winding current
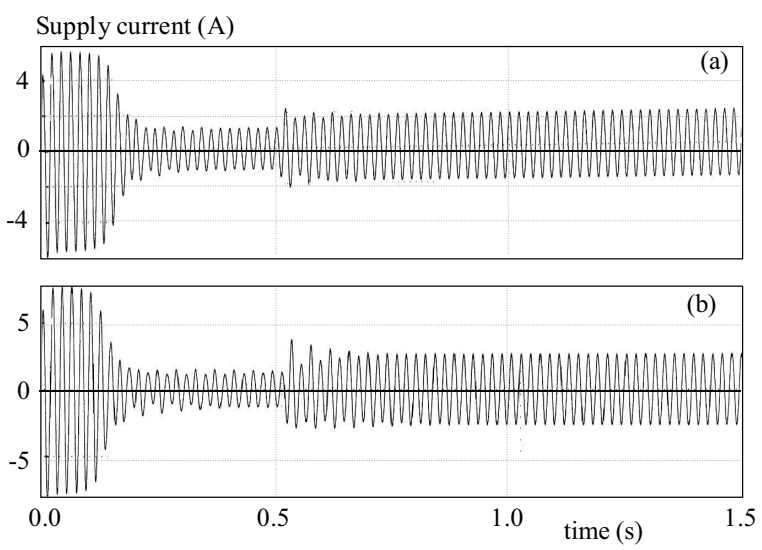

Fig. 13. Transient characteristics of supply current

value of 440 V. In Simulink model for both motor models basic and optimized, currents in the auxiliary winding are lower than in analytical models. Simulink block of the single phase motor operates with capacitor resistance and capacitance in the auxiliary winding. Since only the capacitance is known for the analyzed motor from the manufacturer data sheet, resistance is calculated approximately and consequently this parameter influences the current in the auxiliary winding and accuracy of the complete model. Another limitation of the asynchronous machine block is that it does not include representation of iron losses and core saturation.

\section{FEM models and results}

Throughout the recent years, FEM has proved to be a valuable tool in analysis of electrical machines in cases when parameters and characteristics of the variety of electromagnetic devices are calculated $[24,25]$. The analysis of the electromagnetic phenomena in the single-phase machines is always a challenging task due to the existence of the two stator windings mutually electromagnetically coupled, which together with the current in the rotor winding, produce an elliptical electromagnetic field in the air gap of the motor. Therefore, a special attention is paid to the proper modeling of the motor with 
Table 7. Comparison of results from Simulink, basic and optimized model

\begin{tabular}{lcccc}
\hline & BM & & & OM \\
Parameter & Math. model & Simulation & Math. model & \begin{tabular}{c} 
Simulation \\
\hline motor starting $s=1$
\end{tabular} \\
Supply current $I_{\mathrm{s}}(\mathrm{A})$ & 3.52 & 3.54 & 5 & 5.64 \\
Main current $I_{\mathrm{m}}(\mathrm{A})$ & 3.89 & 3.54 & 5.4 & 5.64 \\
Auxiliary current $I_{\mathrm{a}}(\mathrm{A})$ & 0.483 & 0.34 & 0.49 & 0.34 \\
motor rated load $s=0.04$ & & & & \\
Supply current $I_{\mathrm{s}}(\mathrm{A})$ & 1.68 & 1.41 & 2.25 & 1.86 \\
Main current $I_{\mathrm{m}}(\mathrm{A})$ & 1.063 & 0.92 & 1.61 & 1.42 \\
Auxiliary current $I_{\mathrm{a}}(\mathrm{A})$ & 0.69 & 0.34 & 0.747 & 0.53 \\
Capacitor voltage $V_{\mathrm{c}}(\mathrm{V})$ & 396 & 354 & 433 & 354 \\
Speed n (rpm) & 2880 & 2900 & 2880 & 2900 \\
\hline & Analytical models & Simulink models \\
Increase of torque & 77 & & & \\
optimized to basic model $(\%)$ & & & 85 & \\
\hline
\end{tabular}

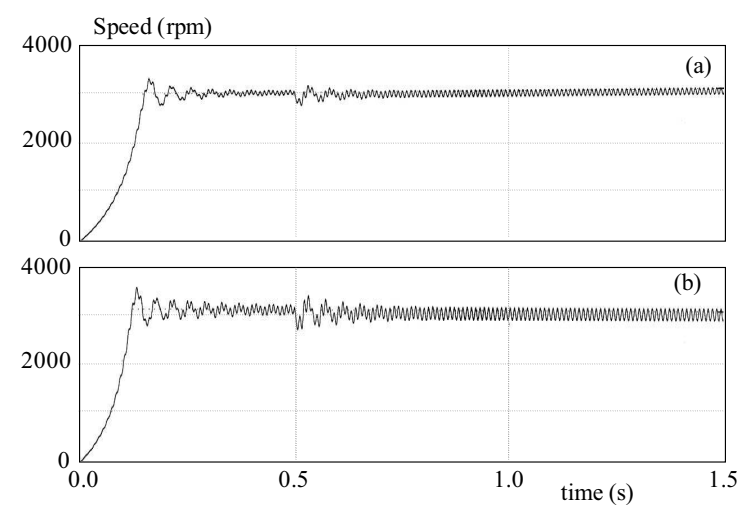

Fig. 14. Transient characteristics of speed
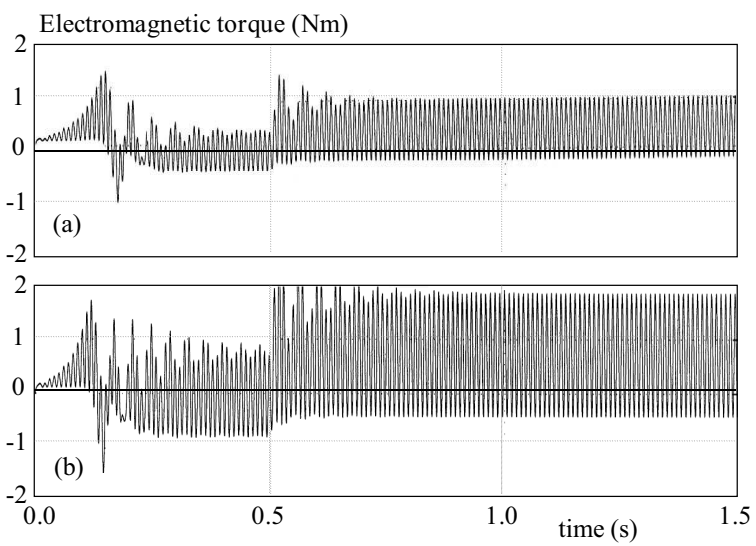

Fig. 16. Transient characteristics of electromagnetic torque

respect to the distribution of the currents in the FEM motor model [26,27]. Phase displacement of the currents in the main and the auxiliary stator winding due to the presence of capacitance in the auxiliary winding is taken into account in the FEM model. The original models of the motor suitable for the FEM analysis have been developed, based on the previously calculated parameters and characteristics of the motor. The FEM analysis is
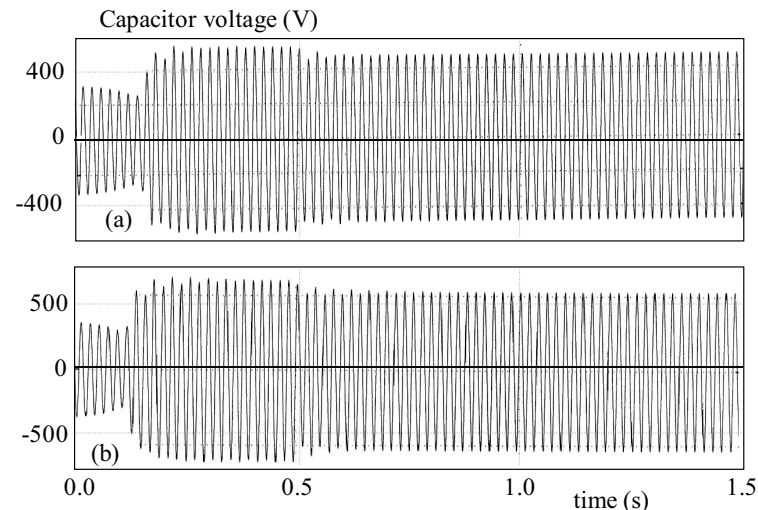

Fig. 15. Transient characteristics of capacitor voltage

divided into three parts: pre-processing, processing and post-processing. In pre-processing part, the object geometry and boundary conditions are defined. For the motor model Dirichlet boundary conditions are chosen $\mathbf{A}=0$, where $\mathbf{A}$ is the magnetic vector potential. This prevents the magnetic flux from crossing the boundary. The properties of all materials are input in the object model, including the magnetization curve $B=f(H)$ of the laminations and the fill factor. In this way, the laminations with hysteresis and eddy currents are taken into consideration for magnetic flux density calculation. In order to determine the value of the magnetic vector potential $\mathbf{A}$ it is necessary to divide the whole domain into a certain number of elements. For the motor model, the finite element mesh is consisted of 49686 nodes and 98954 elements (Fig. 17).

In accordance to results from Table 5, in FEM model currents in stator windings are entered, while the current in rotor winding is freely induced, correspondingly to the motor slip. Furthermore, motor parameters of the corresponding model and materials characteristics are entered as well. As an output from the FEM model of the motor 


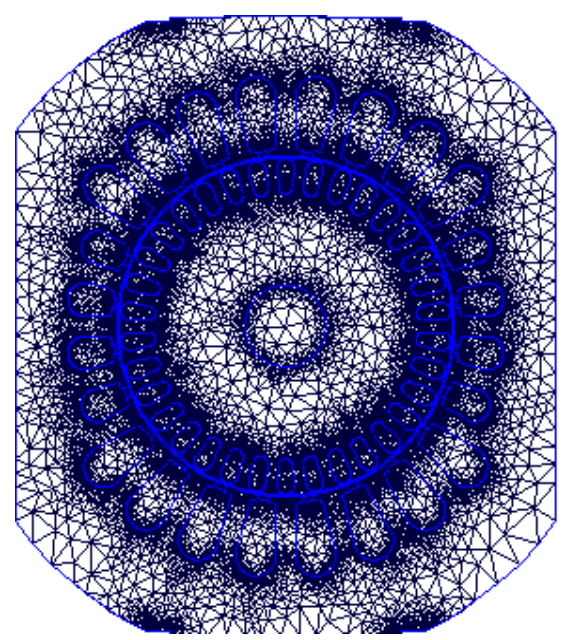

Fig. 17. Finite element mesh at motor cross - section

magnetic flux density in motor cross-section is obtained. It allows parts of motor core with high saturation to be detected and motor construction to be improved by introducing different design variants. Magnetic flux density in motor cross-section is calculated from the FEM model of the motor, a parameter that cannot be exactly calculated by analytical models. Figure 18 provides the distribution of the magnetic flux density in motor cross-sections at noload for both motor models-basic and optimized, while Figs. 19 and 20 present flux density distribution at rated load and locked rotor correspondingly.

Figure 21 presents normal component of magnetic flux density distribution at rated load in the air gap of the motor models. From Figs. 18 to 20 can be concluded that at certain points of the cross-section of OM occur high levels of the magnetic flux density due to the increased currents in all motor windings. In order to reduce these high values of the flux density in OM, it is necessary to use high-quality magnetic materials. The values of the magnetic flux density in the motor air-gap calculated by FEM are confirming the assumed average value of the magnetic flux density of $0.7 \mathrm{~T}$ in the mathematical model of the motor.

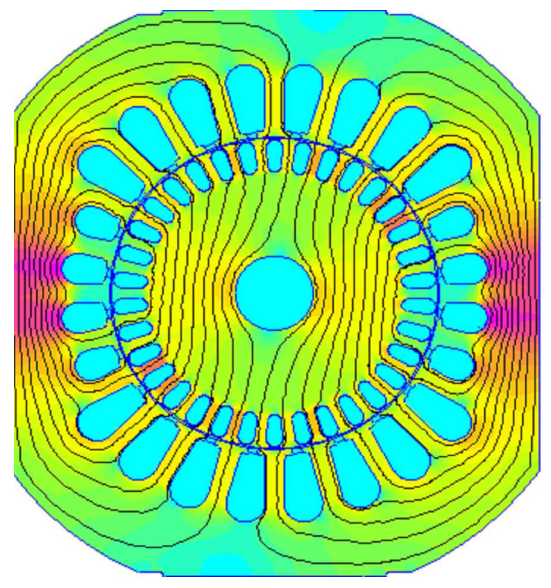

(a)

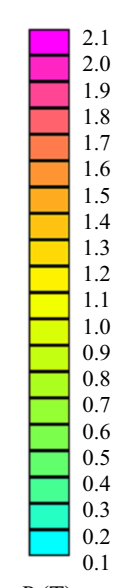

$B(\mathrm{~T})$

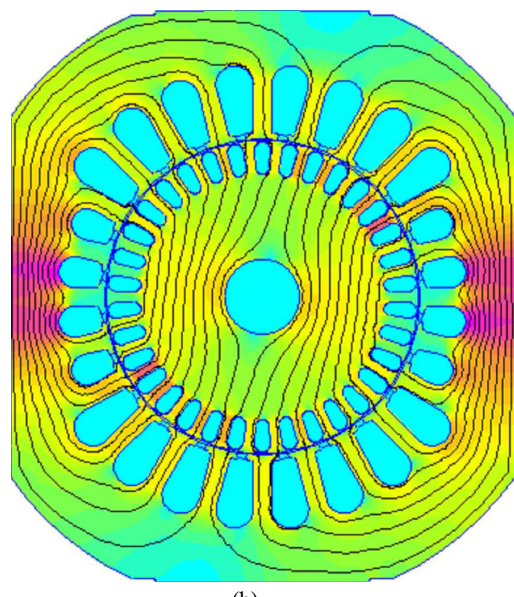

(b)

Fig. 18. Flux density distribution at no-load

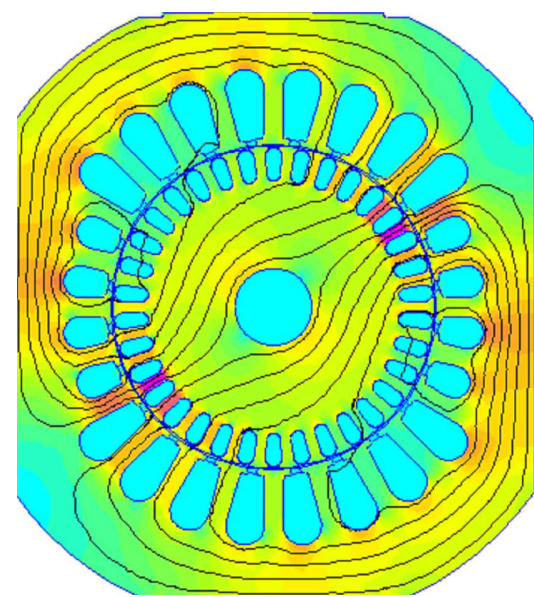

(a)

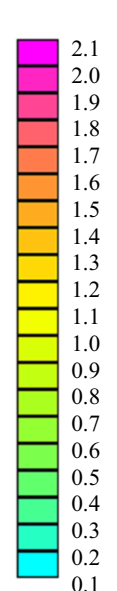

$B(\mathrm{~T})$

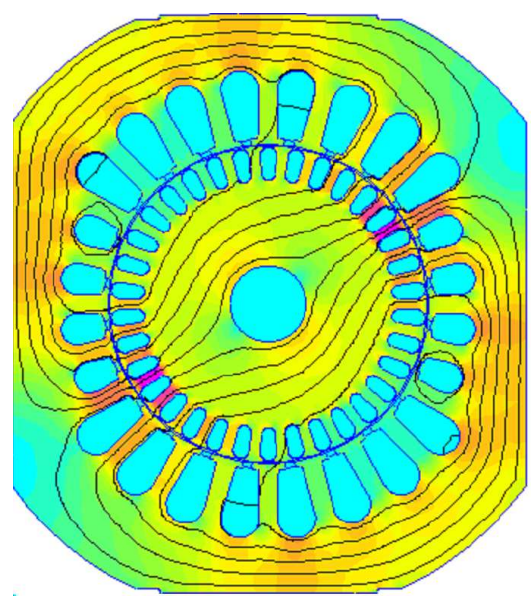

(b)

Fig. 19. Flux density distribution at rated load 


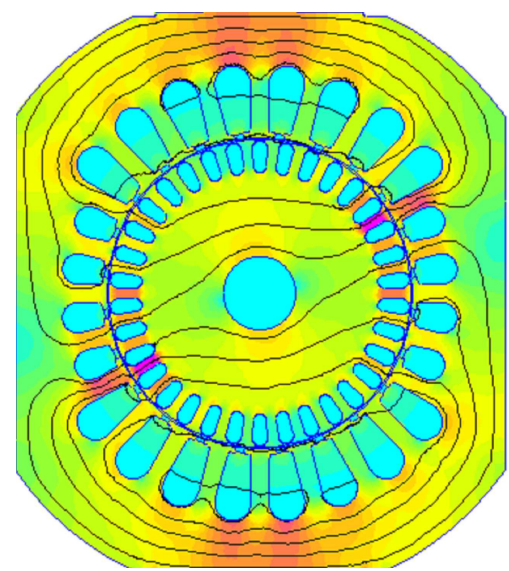

(a)

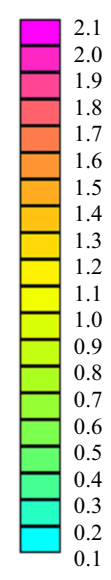

$B(\mathrm{~T})$

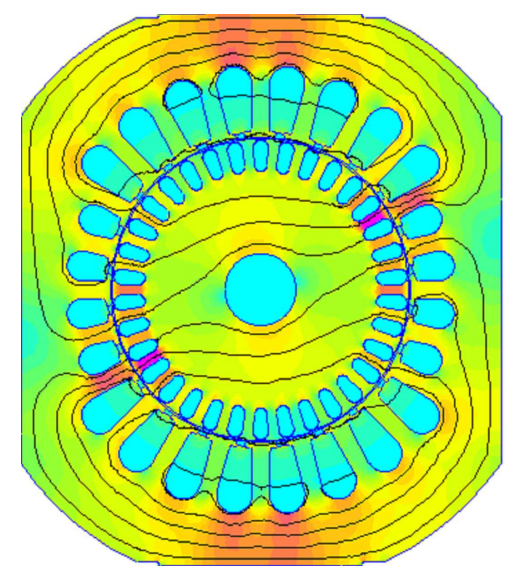

(b)

Fig. 20. Flux density distribution at locked rotor
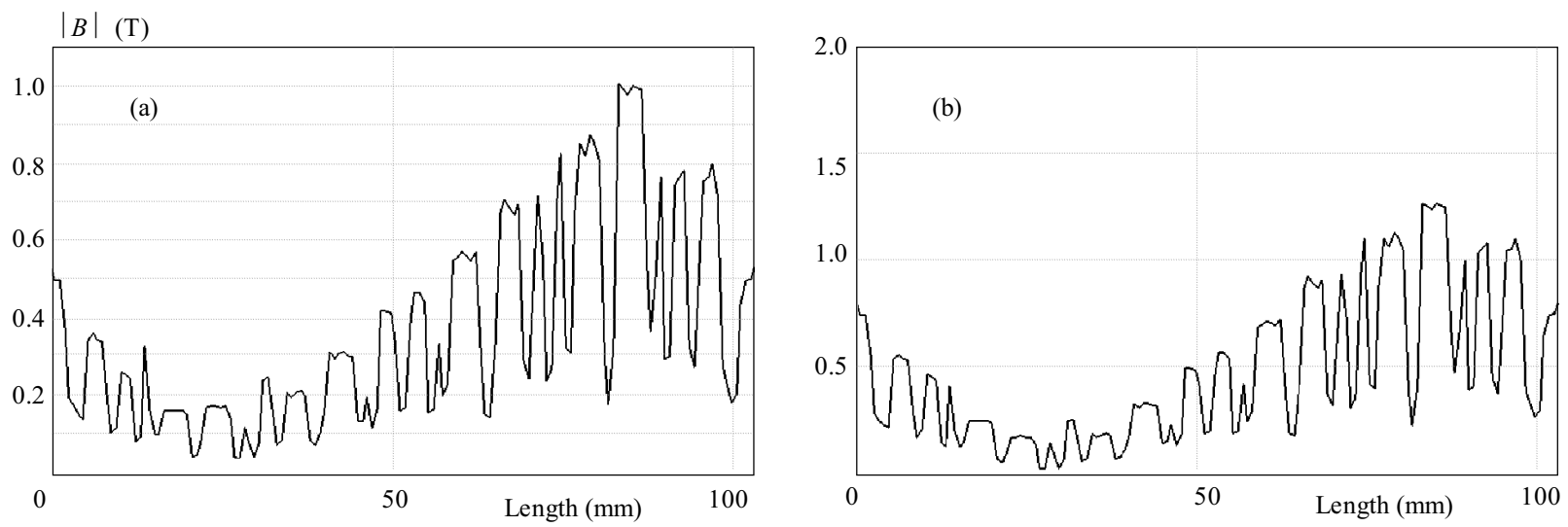

Fig. 21. Flux density distribution in the air gap at rated load

\section{Conclusion}

The purpose of this study is to improve the operating characteristics of permanently split capacitor motor at different working conditions. The method of Genetic Algorithms is applied as optimization tool for maximization of the output torque during nominal operation and motor starting. A newly derived mathematical model of the motor is applied in a software program of Genetic Algorithm with three input variable parameters: turns ratio of main and auxiliary stator winding, flux density in motor air gap and the length of the stator core. The optimization results demonstrate an increase of the output torque at rated load from $0.41 \mathrm{Nm}$ to $0.732 \mathrm{Nm}$ and increase of the starting torque from $0.107 \mathrm{Nm}$ to $0.12 \mathrm{Nm}$. Even a more significant increase of the starting torque may be achieved by increasing the capacitance in the auxiliary winding [3]. However, this issue is not addressed here. It will be subject of further research of the authors. The increase of the output torque is mainly result of the increased motor currents and power consumption. The output power also increases, leading to the improved efficiency of the optimized model. Yet, the increase of currents in motor windings is within permitted limits of the cross-section of the copper conductor. Transient performance characteristics of the both motor models are analyzed in Simulink. That part of the analysis has demonstrated the increase of the electromagnetic torque in the optimized motor model, which results in reduced acceleration time. The Simulink results for the motor currents, speed and voltage of the capacitor are compared with the results of the mathematical models of the motor. They are similar and confirm the accuracy of both proposed mathematical models of the motor: the basic and the optimized one. Magnetic flux density in both motor models is calculated by FEM. Obtained results from the FEM motor models allow the parts of the magnetic core with high saturation to be detected and the construction of the motor to be further improved by using high quality magnetic materials. Numerical models are subject to software limitations as transient characteristics of torque and currents cannot be obtained from them. Authors' further research will be focused on expanding the motor numerical model by the aid of advanced FEM software and obtaining the transient characteristics of torque and currents and their respected average or rms values. Obtained motor characteristics are highly dependent on the accurate calculation of the motor parameters. As inductances are calculated using mathe- 
matical formulas that give only approximate results, the next step in the research of the authors will be also their calculation with numerical methods.

\section{REFERENCES}

[1] E. S. Hamdi, Design of Small Electrical Machines, John Wiley \& Sons, New York 1994, pp. 115-155.

[2] K. Makowski and M. J. Wilk, "Optimization of a Single-Phase Capacitor Induction Motor by Applying a Surrogate Field-Circuit Model", COMPEL, vol. 33, no. 6, pp. 1891-1903, 2014.

[3] L. Petkovska and G. Cvetkovski, "FEM based Assessment of Capacitor Sizing Characteristics of a Single-Phase Induction Motor", Prezglad Elektrotechniczny, vol. 86, no. 12, pp. 113-116, 2010.

[4] S. Sobhani, H. Yaghobi and M. Samakoosh, "Optimize Efficency and Torque Single-Phase Induction Motor by Adjusting the Design Parameters", 12-th International conference Enviroment and Electrical Engineering, Wroclaw, pp. 237-241, 2013.

[5] S. Subramanian and R. Bhuvaneswani, "Optimal Design of Single-Phase Induction Motor using Particle Swam Optimization", COMPEL, vol. 26, no. 2, pp. 418-430, 2007.

[6] I. Boldea, S.A.Nasar, The Induction Machines Design Handbook, Boca Raton, CRC Press, 2010, pp. 791-811, pp. 805-807.

[7] W. H. Yeadon, A.W.Yeadon, Handbook of Small Electric Motors, New York, McGraww-Hill, 2003, pp. 6-1-6-45.

[8] I. E. Davidson, "Performance Calculation of a Shaded-Pole Single Sided Linear Induction Motor Using Symmetrical Components and Finite Element Method", Journal Electromotion, vol. 4, no. 4, pp. 139-145, 1997.

[9] M. Popescu, T. J. Miller, M. McGilp, G. Strappazzon, N Traivillin and R. Santarossa, "Asynchronous Performance Analysis of a Single-Phase Capacitor-Start, Capacitor-Run Permanent Magnet Motor", IEEE Transactions on Energy Conversion, vol. 20, no. 1, pp. 142-150, 2005.

[10] E. F. Fuchs, A. J. Vandenput, J. Holl and C. White, "Design Analysis of Capacitor-Start, Capacitor-Run Single-Phase Induction Motor", IEEE Transactions on Energy Conversion, vol. 5, no. 2, pp. 327-336, 1990.

[11] N. A. Ahmed, "Three Phase Induction Motor Operating from a Single Phase-Supply with Electronically Controlled Capacitor", Electric Power Systems Research, vol. 73, no. 2, pp. 121-128, 2005.

[12] A. Leicht and K. Makowski, "Analysis of a Single-Phase Capacitor Motor Operating at Two Frequencies, Archives of Electrical Engineering, vol. 61, no. 2, pp. 251-266, 2012.

[13] T. Bäck, Evolutionary Algorithms Theory and Pracice, Oxford Univeristy Press, Oxford, 1996.

[14] D. B. Fogel, Evolutionary Computation: Toward a New Philosophy of Machine Intelligence, Piscataway, NJ, 1995.

[15] S. Dong-Joon, Ch. Dong-Hyeok, Ch. Jang-Sung and J. HyunKyo, "Efficiency Optimization of Interior Permanent Magnet Synchronous Motor Using Genetic Algorithms", IEEE Transactions on Magnetics, vol. 33, no. 2, pp. 1880-1883, 1997.
16] Keun-young, Yoon and Byung-il Kwon, "Efficiency Improvement for Concentrated Flux IPM Motors for Washing Machines", Journal of Electrical Engineering Technology, vol. 9, no. 4, pp. 1277-1282, 2014

[17] H. Saavedra, J. R. Riba and L. Romeral, "Multi-Objective Optimal Design of a Five-Phase Fault-Tolerant Axial Flux PM Motor", Advances Electrical and Computer Engineering, vol. 15, no. 1, pp. 69-76, 2015.

[18] V. Sarac, L. Petkovska, M. Cundev and G. Cvetkovski, "Comparison between two Target Functions for Optimization of Single-Phase Shaded Pole Motor using Method of Genetic Algorithms", Journal of Materials Processing Technology, vol. 161, no. 1-2, pp. 89-95, 2005.

19] R. Campenau and M. Cernat, "Two Speed Single Phase Induction Motor with Electronically Controled Capacitance", Advances Electrical and Computer Engineering, vol. 14, no. 3, pp. 137-140, 2014.

[20] The MATLAB compiler user's guide, Mathworks Handbook, Mathworks, 2005.

21] K. Makowski and J. M. Wilk, "Determination of Dynamic Characteristics of the Single Phase Capacitor Induction Motor", Prezglad Electrotechniczny, vol. 87, no. 5, pp. 231-237, 2011.

[22] K. Makowski and M. J. Wilk, "Experimental Verification of Field-Circuit Model of a Single-Phase Capacitor Induction Motor", Prezglad Electrotechniczny, vol. 88, no. 7b, pp. 116-118, 2012.

[23] S. Masic, J. Corda and S. Smaka, "Computation of Static, Steady-State and Dynamic Characteristics of Switched Reluctance Motor", Automatika, vol. 43, no. 3-4, pp. 109-117, 2002.

[24] E. Hüner, M. C. Aküner and U. Demir, "A New Approach Application and Design of Toroidal Axial-Flux Permanent Magnet Open-Slotted NN type", Tehnički vjesnik, vol. 22, no. 5, pp. 1193-1198, 2015.

[25] T. Vaimann, A. Belachen and A. Kallase, "Changing the Magnetic Flux Density Distribution a Squirrel-Cage Induction Motor with Broken Bars", Elektronika ir Elektrotechnika, vol. 20, no. 7, pp. 11-14, 2014.

[26] Y. Sun and D. Y. Lee, "Numerical Analysis of Single Phase Induction Motors by using Circuit Equations Coupled with Magnetic Field Distribution", Journal of Magnetic, vol. 18, no. 3, pp. $255-259,2013$.

[27] V. Hrabovcova and P. Rafajdus, "Radial Magnetic Forces of Single Phase Permanent Split-Capacitor Motor", Journal of Electrical Engineering, vol. 57, no. 4, pp. 185-192, 2006.

Received 23 April 2017

Vasilija Sarac, associate professor of the Faculty of Electrical Engineering at University Goce Delcev, Stip, Republic of Macedonia. Her main research interests include design, simulation and optimization methods in electrical machines and power converters.

Goce Stefanov, assistant professor of the Faculty of Electrical Engineering at University Goce Delcev, Stip, Republic of Macedonia. His main research interests include design, simulation and optimization methods in power converters and electrical machines. 